\title{
Transdermal delivery systems in cosmetics
}

\author{
Byel Kim ${ }^{1,2+}$, Hang-Eui Cho ${ }^{1,3+}$, Sun He Moon ${ }^{1,4}$, Hyun-Jung Ahn ${ }^{1,5}$, Seunghee Bae ${ }^{1}$, Hyun-Dae Cho ${ }^{3 *}$ and \\ Sungkwan $\mathrm{An}^{1 *}$ (D)
}

\begin{abstract}
Transdermal delivery systems have been intensively studied over the past 2 decades, with the focus on overcoming the skin barrier for more effective application of pharmaceutical and cosmetic products. Although the

cosmeceutical industry has made a substantial progress in the development and incorporation of new and effective actives in their products, the barrier function of the skin remains a limiting factor in the penetration and absorption of these actives. Enhancement via modification of the stratum corneum by hydration, acting of chemical enhancers on the structure of stratum corneum lipids, and partitioning and solubility effects are described. This review summarizes the advances in the development and mechanisms of action of chemical components that act as permeation enhancers, as well as the advances in appropriate vehicles, such as gels, emulsions, and vesicular delivery systems, that can be used for effective transdermal delivery.
\end{abstract}

Keywords: Transdermal delivery system, Chemical enhancers, Formulations, Cosmetics

\section{Background}

For thousands of years, people have applied various substances on their skin to obtain therapeutic effects, and in the modern era, various topical formulations have been developed to enhance the skin appearance and treat various conditions (Benson 2005). Currently, with the increased consumer interest in healthy-looking skin, there is an increasing demand for products that supply multiple benefits with minimal effort. Modern consumers expect latest technological advances with innovative formulations that contain various proven actives (Patravale and Mandawgade 2008). As a result, formulations that promote skin permeability by actives are driving new product development in the cosmetic industry.

Following the placement of a therapeutic formulation on the skin, the actives are required to penetrate through the stratum corneum (SC) into the viable tissue. To understand the transdermal delivery of actives within the skin structure, some understanding of skin physiology and the factors affecting transdermal delivery are required. For effective delivery of beneficial ingredients

\footnotetext{
* Correspondence: color@cosmecca.com; ansungkwan@konkuk.ac.kr ${ }^{\dagger}$ Byel Kim and Hang-Eui Cho contributed equally to this work.

${ }^{3}$ Creative Innovation Research Center, Cosmecca Korea, Co., Ltd, 331

Panggyo-ro, Bundang-gu, Seongnam-si 13488, Republic of Korea

${ }^{1}$ Department of Cosmetics Engineering, Graduate School of Konkuk

University, 120 Neungdong-ro, Gwangjin-gu, Seoul 05029, Republic of Korea Full list of author information is available at the end of the article
}

into the skin cells, the barrier function of the skin must be selectively overcome. The most common and convenient method for overcoming this barrier function is the use of additives such as chemical enhancers. These compounds can "piggyback" the actives into the SC or make changes in the SC structure that increase its permeability to the actives. To date, most research on chemical penetration enhancers has studied their addition to formulations to influence the permeability of various active compounds (Moore and Rerek 2000).

In this review, the effects and mechanisms of several chemical enhancers are discussed, and we summarize the trends in the development of appropriate formulations for enhancing the permeation of active ingredients into the skin. To better understand the potential of permeation enhancers in skin delivery systems, we will first introduce the general issues concerning transdermal permeation.

\section{SC, the main barrier of the skin}

The skin primarily comprises the three layers: epidermis, dermis, and subcutaneous tissue. The epidermis contains five different cell strata. The SC, which is the outermost "horny" layer of the epidermis, typically comprises 1015 histologically distinguishable layers of corneocytes that are each $\sim 1 \mu \mathrm{m}$ in thickness (Scheuplein 1967; Katz and Poulsen 1971; Anderson and Cassidy 1973; 
Holbrook and Odland 1974). The corneocytes are flattened, densely packed, and metabolically inactive cells that form a waterproof barrier. The cell membranes are so tightly joined that there is hardly any intercellular space through which polar non-electrolyte molecules and ions can diffuse (Hsieh 1994; Fox et al. 2011).

The SC has, therefore, been described as a brick walllike structure with the keratin-rich corneocytes being the "bricks" and the intercellular lipid matrix being the "mortar" (Michaels et al. 1975). During epidermal differentiation to form the SC, the lipid composition changes from polar to neutral in nature. As a result, the bulk of the SC lipids are neutral (60-80\%), with sphingolipids (15-35\%) and a small number of polar lipids comprising the rest (Lampe et al. 1983). These lipids exist in a continuous lipid phase that occupies about $20 \%$ of the SC volume and is arranged in multiple lamellar structures. A remarkable feature of the SC is the lack of phospholipids and the preponderance of ceramides (41\%), cholesterol (27\%), and cholesteryl esters (10\%) together with fatty acids (9\%) and cholesteryl sulfate (1.9\%) (Wertz and Schwartzendruber, 1989). Both saturated and unsaturated fatty chains form part of the neutral lipid species, with unsaturated chains predominating in the SC except for the free fatty acid fraction (Barry 1987). In the initial layers of the SC, these components are arranged to form broad intercellular lipid lamellae, which then associate into lipid bilayers, with the hydrocarbon chains aligned and the polar head groups dissolved in an aqueous layer (Mathur et al. 2010). The hydrocarbon chains are arranged into regions of crystalline, lamellar gel, and lamellar liquid crystal phases, thereby creating various domains within the lipid bilayers (Bouwstra et al. 1991).

\section{Routes of permeation into the SC}

There are three possible pathways for epidermal penetration of active compounds (Ghaffarian and Muro 2013). These are appendageal (intercellular) penetration through the hair follicle or via the sebaceous and/or sweat glands, and transcellular (intracellular) permeation through the corneocytes and intercellular lipid matrix. The latter route allows a straight path through the SC into the lower levels of the epidermis, and finally, the dermis below. It is generally accepted that because the appendages (hair follicles and glands) comprise only a fractional area (e.g., $\sim 0.1 \%$ of the forearm skin (Otberg et al. 2004)) for permeation, their contribution to epidermal permeation is usually small (Scheuplein 1967). This implies that the transcellular route comprises the main transepidermal pathway.

A molecule traversing via the transcellular route must partition into and diffuse through the corneocytes, but to move between corneocytes, the molecule must also partition into and diffuse through the estimated 4-20 lipid lamellae between each of these cells (Elias et al. 1983). The transcellular route, therefore, requires the negotiation of multiple hydrophilic and hydrophobic domains (Fig. 1).

Thus, the intercellular lipid matrix plays a major role in the barrier function of the SC. As a result, the majority of research aimed at optimizing the permeation of the skin by actives has focused on the contribution of lipids to barrier function, manipulation of the solubility of the lipid domain, and alteration of the ordered structure of the SC.

\section{Factors affecting the efficiency of transdermal delivery systems}

Barry (1983) suggested that factors affecting the drug permeation rate through the SC can be represented by the following steady-state flux equation:

$$
\frac{\mathrm{dm}}{\mathrm{dt}}=\frac{D C_{0} K}{h}
$$

where $C_{0}$ is the constant donor drug concentration, $K$ is the partition coefficient of a solute between the membrane and the bathing solution, $D$ is the diffusion coefficient, and $h$ is the membrane thickness.

Thus, effective penetration enhancers can increase transdermal drug delivery by (Alexander et al. 2012) increasing the diffusion coefficient of the drug in the SC, (Anderson and Cassidy 1973) increasing the drug concentration in the vehicle, (Anton and Vandamme 2011) improving the partitioning between the drug formulation and the SC, and (Aqil et al. 2007) decreasing the skin thickness, which is least likely (Williams and Barry, 2004).

There are several factors influencing the suitability of an agent for incorporation in a transdermal delivery system (TDS) (Pathan and Setty 2009). These include adequate solubility in oil and water such that the membrane concentration gradient would be high, potency of the actives (dose $<50 \mathrm{mg} /$ day or ideally, $<10 \mathrm{mg} /$ day), low molecular weight ( $<500$ Daltons), high lipophilicity ( $\log \mathrm{P}$ in the range of $1-3)$, a low melting point $\left(<200^{\circ} \mathrm{C}\right)$, and two or less hydrogen-bonding groups.

Variables that can account for the observed differences in transdermal permeation between individuals as well as between sites on the same individual include variations in the skin structure, thickness, lipid content, perfusion rate into the dermis, and enzyme activity (Thomas and Finnin 2004). Variability in dosing has also been observed between different skin types, skin temperatures, states of the skin (normal, abraded, or diseased), areas of application, contact times, degrees of skin hydration, and pretreatments of the skin (Roskos et al. 1989; Reed et al. 1995; Alexander et al. 2012). 


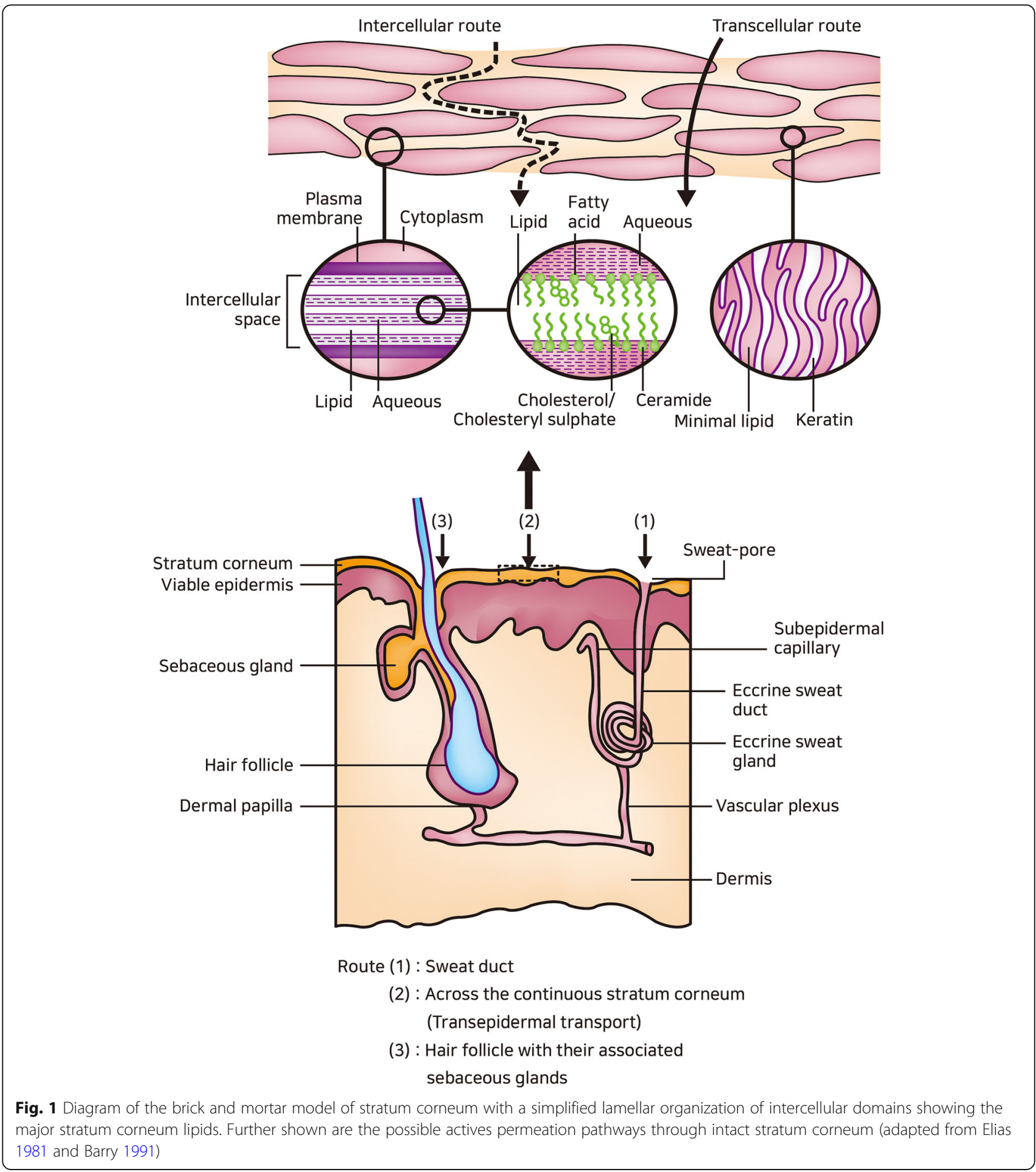

\section{Chemical enhancers}

To facilitate the passage of molecules through the SC, transdermal permeation enhancers have been extensively studied. To date, more than 350 chemicals have been demonstrated to enhance skin permeability (Karande et al. 2005), including terpenes, sulfoxides, laurocapram, pyrrolidones, fatty acids, fatty alcohols, alcohols such as glycol, surfactants, and urea (Chen et al. 2014). These compound classes are very different with respect to their chemical and physical properties and are therefore expected to influence the molecular properties of the SC in various ways (Williams and Barry 2012).

Chemical enhancers are already included in a large number of dermatological, transdermal, and cosmetic 
products to help enhance the dermal absorption of lipophilic and hydrophilic active ingredients (Yang et al. 2011). Chemical enhancers that aid the absorption of co-administered moieties are believed to improve the solubility of actives within the SC or increase the fluidity of the intercellular lipid bilayers (Walker and Smith 1996). These compounds are proposed to act via one or more of three potential mechanisms according to the lipid-protein-partitioning theory; enhancers can act by altering skin lipids and/or proteins and/or by affecting partitioning behavior (Barry 1991). On the other hand, Ogiso and Tanino (2000) suggested four possible mechanisms for the effect of enhancers: (Alexander et al. 2012) an increase in the fluidity of the SC lipids and concomitant reduction in the diffusional resistance to permeants, (Anderson and Cassidy 1973) the removal of intercellular lipids and dilation between adherent cornified cells, (Anton and Vandamme 2011) an increase in the thermodynamic activity of drugs in vehicles, and (Aqil et al. 2007) the exfoliation of SC cell membranes, which leads to the dissociation of adherent cornified cells and elimination of the barrier function.

Generally, enhancers that alter the polar pathway of permeation cause protein conformational changes or solvent swelling, whereas fatty acid enhancers increase the fluidity of the lipid portion of the SC. Some enhancers act on both the polar and non-polar pathways by altering the multilaminate pathway for penetration (Kanikkannan et al. 2000). The various chemical enhancers known to facilitate the skin penetration of cosmetic ingredients are discussed below.

\section{Water (hydration)}

Water is the safest and most common penetration enhancer used for transporting pharmaceutical and cosmetic formulations into the skin (Mckenzie and Stoughton 1962). Hydrating the skin or using moisturizers is the easiest way for effective delivery of hydrophilic molecules (Trommer and Neubert 2006). Furthermore, water molecules act on inter- and intracellular pathways to enhance the permeation of hydrophilic and lipophilic drugs (Barry 1987). Water, owing to its polar nature, likely interacts with the polar head groups of the lipid bilayer, thereby disrupting lipid packing on the polar plane (Barry 1987). Therefore, under hydrated conditions, a small fraction of the SC lipid and protein components becomes fluid, which can be further enhanced by the addition of small foreign compounds. Increased fluidity leads to higher permeability of polar and apolar compounds (Pham et al. 2016).

Compounds such as glycerol and urea are constituents of the so-called natural moisturizing factor within the corneocytes. Urea promotes transdermal permeation by facilitating hydration of the SC and by forming hydrophilic diffusion channels within the barrier (Wong et al. 1989). Urea and glycerol are polar compounds that are not expected to partition into the hydrophobic regions of the lipids, but rather locate in the aqueous regions between the lipid lamellae as well as inside the corneocytes. Urea and glycerol have also been shown to have the strongest fluidizing effect on the terminal segments of the cornoedesmosomes (the protein "rivets" that hold the corneocytes together) among all compounds investigated (Pham et al. 2016).

\section{Alcohols}

Alcohols act via a number of mechanisms to influence transdermal penetration. Solvents such as ethanol and propylene glycol are frequently used as enhancing vehicles-they are not only penetration enhancers but also have good solvating power and are thus frequently used as co-solvents (Sugibayashi et al. 1992).

Ethanol is the most commonly used alcohol as a transdermal penetration enhancer. Ethanol has been suggested to induce modifications of the polar head region of the lipid bilayer (Ghanem et al. 1992). It penetrates the intercellular lipid matrix and increases its fluidity, the latter resulting in decreased density of the lipid lamellae (Verma and Pathak 2010). Ethanol pretreatment of the skin usually increases the permeation of hydrophilic compounds, while decreasing that of hydrophobic compounds (Sugibayashi et al. 1992).

The alkyl chain length of fatty alcohols (or alkanols) is an important parameter in the promotion of permeation (Friend et al. 1988). Disruption of the SC integrity through the extraction of biomolecules by the more hydrophobic alcohols more than likely also contributes to enhanced mass transfer through the SC.

\section{Surfactants}

Surfactants are amphiphilic molecules composed of a lipophilic alkyl chain connected to a hydrophilic head (Morrow et al. 2007). Surfactants are major ingredients in skin detergents, soaps, and cleansers and are also found in many existing therapeutic and cosmetic preparations. Usually, surfactants are added to formulations to solubilize lipophilic active ingredients, and they, therefore, also have the potential to solubilize lipids within the SC (Williams and Barry 2012). Surfactants can enhance skin permeability by partitioning into the epithelial cell membranes and disrupting the packing of membrane lipids, forming structural defects that reduce membrane integrity (Swenson and Curatolo 1992). Agents that alter cell membrane permeability in a way that disrupts normal extracellular-intercellular ion gradients may, however, be cytotoxic, since various cellular functions depend on the maintenance of transmembrane ion gradients (Aungst 2012). 
The effect of surfactants on skin permeation depends on the concentration and type of surfactant. In general, anionic surfactants are more effective than cationic and nonionic surfactants in enhancing skin penetration by target molecules. Some anionic surfactants interact strongly with both keratin and lipids, whereas the cationic surfactants interact with the skin proteins via polar interactions and hydrophobic binding, which disorders SC lipid organization. The critical micelle concentration of nonionic surfactants with an uncharged polar head group is lower than that of the corresponding charged surfactants, and partly due to this, such surfactants are generally less irritating to the skin and are overall better tolerated than anionic and cationic surfactants (Tharwat 2013; Som et al., 2012).

\section{Fatty acids}

Percutaneous drug absorption can be increased by a wide range of long-chain fatty acids, which are carboxylic acids with typically long, unbranched aliphatic tails. Several studies have demonstrated that the alkyl chain length of fatty acids affects percutaneous drug absorption (Morimoto et al. 1996).

The low molecular weight alkanols $(N \leq 6)$ may act as solubilizers which enhance the solubility of drug in the fatty matrix of the SC. The effectiveness of fatty acid esters in enhancing the skin permeation of a drug also depends upon the alkyl chain of the fatty acid itself. An increase in the number of $\mathrm{CH}_{2}$ groups, from methyl to propyl, in the esters of myristic acid were shown to yield a proportional increase in the skin permeation rate of a test drug, whereas a slight decrease in skin permeation was observed as the alkyl chain length in the esters of capric acid was increased (Chien et al. 1988).

Polyunsaturated fatty acids, such as linoleic, alphalinolenic, and arachidonic acids, enhance the skin permeation to a greater degree than monounsaturated fatty acids. Indeed, unsaturated fatty acids are more effective in enhancing the percutaneous absorption of drugs than their saturated counterparts (Chi et al. 1995; Kanikkannan and Babu 2015). Fatty acid enhancers interact with and modify the lipid domains of the SC, as would be expected for a long-chain fatty acid with a cis-configuration (Williams and Barry 2012).

Oleic acid is very commonly used as a chemical penetration enhancer and its mechanism of action has been well described in the literature as fluidization or delipidization of the SC. The increased fluidity creates permeable pores that eventually result in reduced resistance toward the permeation of polar molecules. Structurally, oleic acid consists of an 18-carbon alkyl chain and a polar head group, and it has been reported to be more effective for hydrophilic permeants (Puri et al. 2017).

\section{Terpenes and terpenoids}

Terpenes are hydrocarbons and that comprise a large and diverse class of organic compounds that are produced by a variety of plants. Terpenoids (sometimes called "terpens") are terpenes containing additional functional groups that are usually O-containing groups (McNaught and Wilkinson 1997). Terpenes and terpenoids included in the list of Generally Recognized As Safe (Sapra et al. 2008) are found in essential oils widely used as medicines and as flavoring and fragrance agents (Williams and Barry 2012). Considerable research is now focusing on the use of natural essential oils and their components as potential permeation enhancers to improve skin permeation (Fox et al. 2011).

In a study conducted by Chantasart et al. (2009) using oxygen-containing terpenes such as menthol, thymol, carvacrol, menthone, and cineole, the terpenes were found to increase the permeation of lipophilic compounds. The author suggested that the mechanisms of permeation enhancement by terpenes and alcohols are essentially the same. A review by Sapra et al. (2008) lauded the benefits of terpenes, describing them as having high percutaneous ability, with a reversible effect on the SC lipids and minimal irritancy and toxicity. Their safety profile arguably makes terpenes the most effective class of absorption promoters for hydrophilic and lipophilic drugs (Aqil et al. 2007).

The activity of terpenes as penetration enhancers is primarily related to their chemical structure and physicochemical properties such as their lipophilicity (Ghafourian et al. 2004), size (Williams and Barry 2012), chirality (Monti et al. 1995), boiling point (Narishetty and Panchagnula 2004), energy of vaporization (Ghafourian et al. 2004), and degree of saturation (Jain et al. 2002; Aqil et al. 2007).

\section{Formulations}

It has been recognized that the vehicle in which the permeant is applied to the skin has a distinct effect on the dermal and transdermal delivery of active ingredients (Otto et al. 2009). Cosmetic and pharmaceutical formulations for topical application are multifaceted and can range from aqueous solutions and suspensions to solid systems (Smith et al. 2002). Many studies have been performed to investigate the effect of various formulations such as gels, microemulsions, nanoemulsions, multiple emulsions, and liquid crystals on transdermal delivery. The type of formulation, the droplet size, the emollient, and the emulsifier, as well as the surfactant organization in the emulsion, may all affect the transdermal absorption of formulations. Some of the most widely used formulations for TDS such as gels, emulsions, and vesicular delivery systems are discussed below. 


\section{Gels}

Gels are semisolid formulations that usually consist of two components: a liquid component that acts as a solvent and a solid component (mostly termed a "gelator") that acts as a gelling agent. Gels are exceptional materials that are both rigid and elastic in nature and have a broad range of applications in cosmetics, medicines, and the food industry (Wichterle and Lím 1960; Dastidar 2008). Gels hydrate the skin by retaining a significant amount of water, thereby permitting greater dissolution of actives and facilitating their transepidermal migration (Rehman and Zulfakar 2014).

\section{Hydrogels}

Hydrogels are three-dimensional hydrophilic polymeric networks, which have the ability to absorb large quantities of water or biological fluids (Brannon-Peppas 1990; Peppas et al. 2000). They consist of an aqueous dispersion medium that is gelled with a suitable hydrophilic agent. Many therapeutic agents are loaded in hydrogels for the purpose of efficient wound healing (Choi et al. 2013).

\section{Organogels}

Organogels are a class of gel composed of a liquid organic phase within a three-dimensional cross-linked network that contains oil or non-polar liquids as a dispersion medium. Many typical organogel components are known to be permeation enhancers, and organogels are thought to act by creating partitions in the lipid bilayers of the SC (Vintiloiu and Leroux 2008).

\section{Bigels}

Bigels are biphasic systems produced by mixing an organogel and a hydrogel together at high shear rates (Lupi et al. 2015). The key features of bigels that make them useful for controlled drug delivery are their ability to deliver both hydrophilic and lipophilic active agents across the SC (Shakeel et al. 2018). Bigels are also easy to prepare and have a good stability. Their enhancement of skin hydration results in cooling and moisturizing effects.

\section{Emulgels}

The presence of a gelling agent in the water phase converts a classical emulsion into an emulgel (Banker 1970). Although traditional gels have many advantages, the delivery of hydrophobic drugs has consistently been a point of concern. To overcome this limitation, emulgels were introduced. Furthermore, emulgels have the benefits of spreadability, adhesion, viscosity, and the highest drug release (Noor et al. 2019).

Recently, nanosuspension-based gels (also called "nanogels") have received considerable attention in the development of topical applications because of their ability to enhance delivery into the skin (Shen et al. 2018).
Proniosomal gels are primarily formulated based on either hydrogels or organogels. Organogel-based niosomal gels have mainly been investigated as vehicles of actives (Gonnet et al. 2010).

\section{Emulsions}

Emulsions are liquid or semisolid mixtures of lipophilic and hydrophilic constituents that have been stabilized into a homogeneous dispersion by a surface-active agent (JeanLouis 2000). Emulsions are widely used in cosmetic and pharmaceutical formulations because of their excellent solubilizing capacities for lipophilic and hydrophilic active ingredients and their application acceptability (Otto et al. 2009).

\section{Microemulsions}

A microemulsion is a mixture of water, oil, and an amphiphile that forms an optically isotropic and thermodynamically stable liquid solution (Danielsson and Lindman 1981). Microemulsions are thermodynamically stable and transparent (or translucent). The oil and water dispersion is stabilized by the amphiphile, which forms an interfacial film of surfactant molecules with a diameter of $<100 \mathrm{~nm}$ (usually 10-50 nm).

Microemulsions are classified into three types: oil-inwater, bicontinuous, and water-in-oil (Boonme 2007). Several recent reports have detailed microemulsion formulations designed for topical or transdermal application (Lawrence and Rees 2012). Microemulsions form spontaneously or with a very low energy input but require a greater amount of surfactant compared with emulsions, which may lead to increased irritancy (Montenegro et al. 2016).

Naturally occurring surfactants and oils remain an attractive option, and the phase behavior and microstructure of microemulsions based on soybean phosphatidylcholine and triglycerides have recently been reported, although propanol was used as the cosurfactant (Flanagan et al. 2006). The preparation of non-toxic microemulsions has also been described for mixtures of isopropyl myristate or orange oil with lecithin (Kahlweit et al. 1995). An interesting alternative approach for the stabilization of microemulsions of octyl monoglucoside has been to employ geraniol, a perfume alcohol $\left(\mathrm{C}_{10} \mathrm{H}_{17} \mathrm{OH}\right)$, as a cosurfactant/cosolvent (Stubenrauch et al. 1997).

\section{Nanoemulsions}

Nanoemulsions consist of very fine oil-in-water dispersions, with a droplet diameter in the range of 20-200 $\mathrm{nm}$ and narrow size distributions (Anton and Vandamme 2011). Nanoemulsions are kinetically but not thermodynamically stable, and their preparation requires expensive, high-energy input methods as they are formed with relatively small amounts of surfactants (Montenegro et al. 2016). The efficacy of nanoemulsions 
is enhanced by the nature and type of surfactant and cosurfactant used (Hussan 2011).

Because nanoemulsions are transparent and typically very fluid, the slightest sign of destabilization is readily apparent. The very small size of the droplets $(\sim 50 \mathrm{~nm}$ in diameter) gives them characteristic properties that are highly valued in cosmetics. As they are transparent, consumers associate nanoemulsions with freshness, purity, and simplicity, and they are easily absorbed by the skin (Sonneville-Aubrun et al. 2004).

There are many similarities between the composition, dimension, structure, and fabrication methods of nanoemulsions and microemulsions, which have led to considerable confusion in the literature about the precise nature of the colloidal dispersion being studied (Anton and Vandamme 2011).

\section{Liquid crystals}

Liquid crystals are an intermediate state between solid and liquid. This is often called a mesomorphic state, where the degree of molecular order is intermediate between that of isotropic liquids, gases, and amorphous solids (McNaught and Wilkinson 1997). Liquid crystals form multilayers around emulsion droplets, decreasing the van der Waals force and increasing the viscosity, which increase emulsion stability (Friberg and Solans 1986). Various bioactive molecules such as chemical drugs, peptides, and proteins can be solubilized in either the aqueous or oil phase of liquid crystals for protection from hydrolysis and oxidation (Guo et al. 2010). Several studies have demonstrated how advantageous it is for formulations to form liquid crystals because they improve the formulation in several aspects: they increase skin hydration, which increases formulation viscosity as a result of molecular reorganization, and they increase the permeability and prolong the release of actives (Iwai et al. 1998; Rodrigues Ueoka and Pedriali 2018). A study by Otto et al. described how emulsifiers arranged in liquid crystalline structures in the water phase enhanced the skin penetration of active ingredients (Otto et al. 2009).

\section{Multiple emulsions}

Multiple emulsions consist either of oil globules dispersed within water globules in an oily continuous phase (o/w/o) or of water globules dispersed within oil globules in a continuous water phase $(\mathrm{w} / \mathrm{o} / \mathrm{w})$. Multiple emulsions, especially w/o/w systems, have shown a potential applicability in controlled release systems for the delivery of active ingredients (McClements et al. 2007).

Several studies using different active ingredients have been performed to compare different types of emulsions (o/w, w/o, and $\mathrm{w} / \mathrm{o} / \mathrm{w}$ ) with identical composition. This allowed the investigation of the effect of the type of emulsion alone without the influence of different formulation ingredients. It was found that the level of skin uptake of glucose and lactic acid, which are both water-soluble compounds, as well as the flux of glucose across the skin, decreased in the following order: $\mathrm{o} / \mathrm{w}>\mathrm{w} / \mathrm{o} / \mathrm{w}>\mathrm{w} / \mathrm{o}$ (Ferreira et al. 1995; Imlmal and Rekax 1995; Otto et al. 2009).

\section{Vesicular delivery systems}

Dermal application of cosmetic actives with properties such as high molecular weight, hydrophilicity, polarity, or susceptibility to enzymatic degradation remains highly challenging. Nano-sized vesicular delivery systems used for drug delivery are of particular interest to the cosmetic industry for this purpose ( $\mathrm{Mu}$ and Sprando 2010). Liquid nano-sized systems are significantly more effective as vehicles for extremely hydrophilic agents than classical enhancer emulsions (Sommer et al. 2018). Liposomes are the most widely used vehicle in the development and production of permeation delivery systems, but several other vehicles have also been investigated.

\section{Liposomes}

Liposomes are well known and often used as vesicular delivery systems for active ingredients in cosmetics (Hougeir and Kircik 2012). They comprise phospholipid membranes arranged in a sphere and are used to encapsulate polar and non-polar actives (Yarosh 1992). First described by Bangham in 1965, liposomes have been prepared with a variety of phospholipids and have been extensively studied in the pharmaceutical and cosmetic industries.

Liposomes are used in cosmetic applications or for transdermal delivery in particular with the expectation that their use will result in an increase in the concentration of active agents within the skin. For example, liposomes encapsulating CoQ10, a powerful antioxidant, have been shown to be beneficial to the skin. Larger vitamins, such as vitamin $\mathrm{E}$, water-soluble vitamins, fatsoluble amino acids, and even chemically formulated active ingredients, can also be successfully encapsulated in liposomes to formulate various skincare products (Soni et al. 2016).

However, although phospholipids offer the advantages of being biodegradable and non-toxic amphiphiles, liposomes have low physical and chemical stability and poor skin permeation limits when used for topical delivery. To increase the stability of liposomes, the concept of proliposomes has been proposed. Proliposomes and proniosomes, which are respectively converted to liposomes and niosomes upon simple hydration, have, therefore, been investigated for transdermal drug delivery. This approach was also extended to tranfersomes and ethosomes, which exhibit superior stability than liposomes (Verma and Pathak 2010). These vesicular delivery vehicles are discussed further below. 


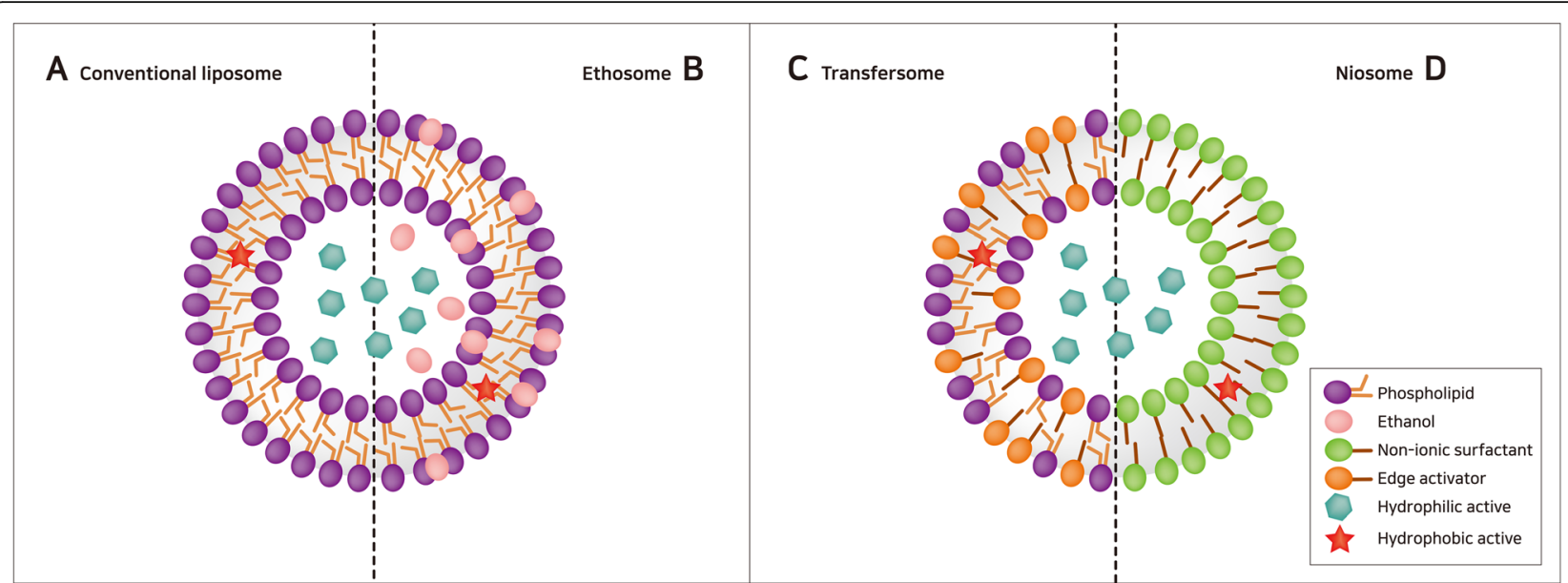

Fig. 2 Schematic representation of the different types of lipid-based vesicular delivery systems. a Conventional liposomes generally consist of a lipid bilayer composed of phospholipids. $\mathbf{b}$ Ethosomes primarily composed of phospholipids and a high concentration of ethanol. $\mathbf{c}$

Transfersomes composed of edge acativators. d Niosomes consist of nonionic surfactant vesicles (adapted from after Hua 2015)

\section{Ethosomes}

Ethosomes are composed mainly of phospholipids (phosphatidylcholine, phosphatidylserine, and phosphatidic acid) and high concentrations of ethanol and water (Fig. 2). The incorporation of ethanol in the lipid vesicles is an alternative approach to fluidize the lipid membrane and thus enhance drug delivery (Touitou et al. 2000). Because of the high ethanol concentration present, the lipid membrane of ethosomes is less tightly packed than conventional vesicles but has equivalent stability, allowing a more malleable structure and improved distribution among SC lipids (Verma and Pathak 2010). The size of ethosome vesicles can be modulated from tens of nanometers to microns (Touitou et al. 2000; Verma and Fahr 2004).

\section{Transfersomes}

Transfersomes ${ }^{\oplus}$, first proposed by Cevc et al. in 1995, are proprietary lipid aggregations that can penetrate efficiently through pores or other biological constrictions that would be confining for other particulates of a comparable size. These malleable vesicles can stretch up to $500 \mathrm{~nm}$ in length to penetrate the SC barrier. This capability is due to the self-adaptable and extremely high deformability of the transfersome membrane (Cevc et al., 1995 and 1996).

Transfersomes and ethosomes incorporating edge activators, such as surfactants, and penetration enhancers, such as alcohols, limonene, oleic acid, and polyols, have been shown to influence the properties of these vesicles and their permeation of the SC (El-Maghraby et al. 2004).

\section{Niosomes}

Niosomes are nonionic surfactant vesicles that selfassemble from hydrated surfactant monomers and have the capacity to deliver hydrophilic, lipophilic, and amphiphilic substances (Handjani et al. 1989; Uchegbu and Florence 1995). Niosomes are similar to liposomes in terms of their structure and physical properties, as they comprise single or double alkyl chain nonionic surfactants with cholesterol (Baillie et al. 1985). Niosomes have the ability to modify the structure of the SC through their surfactant properties, resulting in the layer becoming looser and more permeable (Geusens et al. 2011).

Niosomes are an effective alternative to liposomes, as they possess greater stability and alleviate other disadvantages associated with liposomes, such as variable purity of the phospholipid constituents and high cost.

Recent advances in liposome modifications appear to have generated increased therapeutic potential. Alterations in their composition and structure result in vesicles with tailored properties. For example, marinosomes are liposomes made with natural marine lipids that have a high concentration of polyunsaturated fatty acids and intrinsic anti-inflammatory properties (Cansell et al. 2007). Ultrasomes are liposomes encapsulating a UV-endonuclease enzyme that recognizes sun damage to the skin and initiates the repair of UV-damaged DNA as well as inhibiting the expression of pro-inflammatory cytokines (Yarosh and Klein 1996; Patravale and Mandawgade 2008). Photosomes protect sun-exposed skin by releasing a lightactivated enzyme (photolyase) extracted from a marine plant, Anacystis nidulans, which helps repair DNA damage (Patravale and Mandawgade 2008). Photosomes encapsulate the photolyase in liposomes and are incorporated in sunscreen products (Decome et al. 2005). 


\section{Newer techniques}

\section{Physical enhancers}

Active methods are beyond the focus of this article, but they have been the subject of a number of recent reviews. Physical forces such as electrical voltage (iontophoresis, electroporation), ultrasound (sonophoresis), microneedles, thermal ablation, magnetophoresis, photomechanical waves, and electron beam irradiation have all been used to overcome the skin barrier (Prausnitz and Langer 2008; Alexander et al. 2012). Device-based approaches to increase skin permeability or provide a driving force for transport appear to be broadly effective at increasing the transdermal delivery of macromolecules (Gratieri et al. 2011). Physical mechanisms generally create micron-scale pores in the $\mathrm{SC}$, enabling transport of very large molecules (Arora et al. 2008).

\section{Combining permeation enhancers}

Potent enhancers can also be potent irritants to the skin at concentrations necessary to induce sufficient penetration enhancement (Lashmar et al. 1989). For the successful delivery of bioactives, scientists have worked on several combinatorial approaches where a physical enhancer and a chemical enhancer are combined, such as chemical-iontophoresis (Bhatia et al. 1997; Kalia and Guy 1997; Pillai and Panchagnula 2003) and chemicalultrasound (Mitragotri et al. 2000; Seto et al. 2010), reported the synergistic effect of this safe, effective, and practical use of TDS (Alexander et al. 2012).

Where synergistic effects can be obtained, the combinatorial approach has the potential for effective permeation enhancement at lower active concentrations than separate approaches (du Toit et al. 2016). For example, the study by Carvalho et al. (2018) about the combination of chemical enhancers incorporated a microemulsion of ethanol, 1,8-cineole, and geraniol and showed that the ethanol and cineole causes an increase in the diffusion and partition coefficients. Karande et al. (2004) proposed an experimental tool, in vitro skin impedance guided by highthroughput screening, to investigate particular mixtures of penetration enhancers for increased skin permeability to macromolecules $(\sim 10 \mathrm{kDa})$, which yielded up to $\sim 100$ fold enhancement without inducing skin irritation. A combination of two or more enhancers may, therefore, not only increase SC permeability but can also increase the safety of the enhancers (Mitragotri 2000).

\section{Conclusions}

The cosmeceutical industry has made great progress in the development and incorporation of new and effective actives in their products. However, the skin, as a primary barrier, plays a special role in protecting the living body from cutaneous exposure to toxic chemicals (El-Kattan et al. 2000). TDS to enhance permeation by altering partitioning into the $\mathrm{SC}$ work by affecting the solubility properties of the skin, thereby increasing the solubility of actives within the SC (Thomas and Finnin 2004). The search continues for an ideal enhancer that is pharmacologically inactive, non-irritant, non-toxic, effective, and cosmetically acceptable (Pfister and Hsieh 1990). Overcoming the skin barrier in a safe and effective way still remains a major challenge for topical applications.

This review has provided an overview of the research to date on the design of permeation enhancers and applicable formulations for TDS in cosmetics. The list of materials and techniques described in this paper is clearly not exhaustive, but it does represent the general strategies involving chemical enhancers, their mechanisms of action, and the vehicles that can facilitate transdermal delivery for cosmetic applications. Further studies on the mechanisms of penetration enhancement, the metabolism of chemicals within the skin, skin toxicity, and the development of novel technologies and appropriate formulations for the delivery of actives, will all facilitate the future development of innovative cosmetic products.

\section{Abbreviations \\ D: Diffusion coefficient; K: The partition coefficient; SC: Stratum corneum; TDS: Transdermal delivery system}

\section{Acknowledgements}

This study was supported by the Cosmecca Korea, Co., Ltd. and Konkuk University research support program.

Authors' contributions

All authors designed the study and analyzed data together, and BK, HEC, SA, and HDC wrote the manuscript. All authors read and approved the final manuscript.

\section{Funding}

There was no funding for this paper.

Availability of data and materials

Not applicable

Ethics approval and consent to participate

Not applicable

Consent for publication

Not applicable

Competing interests

The authors declare that they have no competing interests.

Author details

${ }^{1}$ Department of Cosmetics Engineering, Graduate School of Konkuk University, 120 Neungdong-ro, Gwangjin-gu, Seoul 05029, Republic of Korea. UH R\&D, A-415 Michuol 12 Gaetbeol-ro, Yeonsu-gu, Incheon 21999, Republic of Korea. ${ }^{3}$ Creative Innovation Research Center, Cosmecca Korea, Co., Ltd, 331 Panggyo-ro, Bundang-gu, Seongnam-si 13488, Republic of Korea. ${ }^{4}$ Yeosiya Beauty Academy, 552 Gonghang-daero, Yangcheon-gu, Seoul 07946, Republic of Korea. ${ }^{5}$ Amorepacific Corporation, 100 Hangang-daero, Yongsan-gu, Seoul 04386, Republic of Korea. 
Received: 19 August 2019 Accepted: 8 January 2020

\section{Published online: 07 April 2020}

\section{References}

Alexander A, Dwivedi S, Ajazuddin, Giri TK, Saraf S, Saraf S, Tripathi DK. Approaches for breaking the barriers of drug permeation through transdermal drug delivery. J Control Release. 2012;164:26-40.

Anderson RL, Cassidy JM. Variation in physical dimensions and chemical composition of human stratum corneum. J Invest Dermatol. 1973;61:30-2.

Anton N, Vandamme TF. Nano-emulsions and micro-emulsions: clarifications of the critical differences. Pharm Res. 2011;28:978-85.

Aqil M, Ahad A, Sultana Y, Ali A. Status of terpenes as skin penetration enhancers. Drug Discov Today. 2007;12:1061-7.

Arora A, Prausnitz MR, Mitragotri S. Micro-scale devices for transdermal drug delivery. Int J Pharm. 2008:364:227-36.

Aungst BJ. Absorption enhancers: applications and advances. AAPS J. 2012;14:10-8.

Baillie AJ, Florence AT, Hume LR, Muirhead GT, Rogerson A. The preparation and properties of niosomes--non-ionic surfactant vesicles. J Pharm Pharmacol. 1985:37:863-8.

Bangham AD, Standish MM, Watkins JC. Diffusion of univalent ions across the lamellae of swollen phospholipids. J Mol Biol. 1965;13:238-52.

Banker GS. The theory and practice of industrial pharmacy. J Pharm Sci. 1970;59:1531.

Barry BW. Dermatological formulations: percutaneous absorption. Drugs Pharm Sci. 1983;18:1-39 https://doi.org/10.1016/0306-3623(84)90021-1.

Barry BW. Mode of action of penetration enhancers in human skin. J Control Release. 1987:6:85-97.

Barry BW. Lipid-protein-partitioning theory of skin penetration enhancement. J Control Release. 1991;15:237-48

Benson HA. Transdermal drug delivery: penetration enhancement techniques. Curr Drug Deliv. 2005;2:23-33.

Bhatia KS, Gao S, Singh J. Effect of penetration enhancers and iontophoresis on the FT-IR spectroscopy and LHRH permeability through porcine skin. J Control Release. 1997:47:81-9.

Boonme P. Applications of microemulsions in cosmetics. J Cosmet Dermatol. 2007;6:223-8

Bouwstra JA, Gooris GS, van der Spek JA, Bras W. Structural investigations of human stratum corneum by small-angle X-ray scattering. J Invest Dermatol. 1991;97:1005-12.

Brannon-Peppas L. Preparation and characterization of crosslinked hydrophilic networks. In: Studies in Polymer Science, vol. 8; 1990. p. 45-66. https://doi. org/10.1016/B978-0-444-88654-5.50008-X.

Cansell MS, Moussaoui N, Mancini M. Prostaglandin $\mathrm{E}_{2}$ and interleukin-8 production in human epidermal keratinocytes exposed to marine lipid-based liposomes. Prostaglandin. 2007;343:277-80 https://doi.org/10.1016/j.jpharm.2007.04.014

Carvalho ALM, Silva JA, AAM L, EDP A, Nunes RS, VHV S, LMC V, de Almeida Leite JR, Leal LB, de Santana DP. Third-generation transdermal delivery systems containing zidovudine: effect of the combination of different chemical enhancers and a microemulsion system. AAPS Pharm Sci Tech. 2018:19:3219-27.

Cevc G, Blume G, Schätzlein A, Gebauer D, Paul A. The skin: a pathway for systemic treatment with patches and lipid-based agent carriers. Adv Drug Delivery Rev. 1996;18:349-78.

Cevc G, Schätzlein A, Blume G. Transdermal drug carriers: basic properties, optimization and transfer efficiency in the case of epicutaneously applied peptides. J Control Release. 1995;36:3-16.

Chantasart D, Pongjanyakul T, Higuchi WI, Li SK. Effects of oxygen-containing terpenes as skin permeation enhancers on the lipoidal pathways of human epidermal membrane. J Pharm Sci. 2009;98:3617-32

Chen Y, Quan P, Liu X, Wang M, Fang L. Novel chemical permeation enhancers for transdermal drug delivery. Asian J Pharm Sci. 2014;9:51-64.

Chi SC, Park ES, Kim H. Effect of penetration enhancers on flurbiprofen permeation through rat skin. Int J Pharm. 1995;126:267-74.

Chien YW, Xu HL, Chiang CC, Huang YC. Transdermal controlled administration of indomethacin. I. Enhancement of skin permeability. Pharm Res. 1988;5:103-6.

Choi SG, Baek EJ, Davaa E, Nho YC, Lim YM, Park JS, et al. Topical treatment of the buccal mucosa and wounded skin in rats with a triamcinolone acetonideloaded hydrogel prepared using an electron beam. Int J Pharm. 2013;447:102-8.

Danielsson I, Lindman B. The definition of microemulsion. Colloids Surf. 1981;3:391-2.

Dastidar P. Supramolecular gelling agents: can they be designed? Chem Soc Rev. 2008;37:2699-715.

Decome L, De Méo M, Geffard A, Doucet O, Duménil G, Botta A. Evaluation of photolyase (photosome) repair activity in human keratinocytes after a single dose of ultraviolet B irradiation using the comet assay. J Photochem Photobiol B. 2005;79:101-8.

du Toit T, Malan MM, Lemmer HJR, Gouws C, Aucamp ME, Breytenbach WJ, Hamman JH. Combining chemical permeation enhancers for synergistic effects. Eur J Drug Metab Pharmacokinet. 2016;41:575-86.

Elias PM. Lipids and the epidermal permeability barrier. Arch Dermatol Res. 1981; 270:95-117.

Elias PM, Grayson S, Lampe MA, Williams ML, Brown BE. The intercomeocyte space. In: Marks R, Plewig G, editors. Stratum Corneum. Berlin Heidelberg:: Springer-Verlag; 1983. p. 53-4. https://doi.org/10.1007/978-3-642-68682-5_7.

El-Kattan AF, Asbill CS, Michniak BB. The effect of terpene enhancer lipophilicity on the percutaneous permeation of hydrocortisone formulated in HPMC gel systems. Int J Pharm. 2000;198:179-89.

El-Maghraby GM, Williams AC, Barry BW. Interactions of surfactants (edge activators) and skin penetration enhancers with liposomes. Int J Pharm. 2004; 276:143-61.

Ferreira LAM, Seiller M, Grossiord JL, Marty JP, Wepierre J. Vehicle influence on in vitro release of glucose: $\mathrm{w} / \mathrm{O}, \mathrm{w} / \mathrm{o} / \mathrm{w}$ and o/w systems compared. J Controlled Release. 1995;33(3):349-56 https://doi.org/10.1016/01683659(94)00099-G.

Flanagan J, Kortegaard K, Neil Pinder D, Rades T, Singh H. Solubilisation of soybean oil in microemulsions using various surfactants. Food Hydrcoll. 2006; 20:253-60.

Fox LT, Gerber M, Du Plessis JD, Hamman JH. Transdermal drug delivery enhancement by compounds of natural origin. Molecules. 2011;16:10507-40.

Friberg SE, Solans C. Surfactant association structures and the stability of emulsions and foams. Langmuir. 1986;2:121-6.

Friend D, Catz P, Heller J, Reid J, Baker R. Transdermal delivery of levonorgestrel I. Alkanols as permeation enhancers in vitro. J Control Release. 1988;7:243-50.

Geusens B, Strobbe T, Bracke S, Dynoodt P, Sanders N, Van Gele M, Lambert J. Lipid-mediated gene delivery to the skin. Eur J Pharm Sci. 2011;43:199-211.

Ghaffarian R, Muro S. Models and methods to evaluate transport of drug delivery systems across cellular barriers. J Vis Exp. 2013;80:e50638.

Ghafourian T, Zandasrar P, Hamishekar H, Nokhodchi A. The effect of penetration enhancers on drug delivery through skin: a QSAR study. J Control Release. 2004;99:113-25.

Ghanem AH, Mahmoud H, Higuchi WI, Liu P, Good WR. The effects of ethanol on the transport of lipophilic and polar permeants across hairless mouse skin: methods/validation of a novel approach. Int J Pharm. 1992;78:137-56.

Gonnet M, Lethuaut L, Boury F. New trends in encapsulation of liposoluble vitamins. J Control Release. 2010;146:276-90.

Gratieri T, Kalaria D, Kalia YN. Non-invasive iontophoretic delivery of peptides and proteins across the skin. Expert Opin Drug Deliv. 2011;8:645-63.

Guo C, Wang J, Cao F, Lee RJ, Zhai G. Lyotropic liquid crystal systems in drug delivery. Drug Discov Today. 2010;15:1032-40.

Handjani RM, Ribier A, Vanlerberghe G, Zabotto A, Griat J. Cosmetic and pharmaceutical compositions containing niosomes and a water-soluble polyamide, and a process for preparing these compositions. Gen Pharmacol. 1989;20;(6):V https://doi.org/10.1016/0306-3623(89)90374-1.

Holbrook KA, Odland GF. Regional differences in the thickness (cell layers) of the human stratum corneum: an ultrastructural analysis. J Invest Dermatol. 1974; 62:415-22.

Hougeir FG, Kircik L. A review of delivery systems in cosmetics. Dermatol Ther. 2012;25:234-7.

Hsieh DS. Drug permeation enhancement - theory and applications. Drug Dev Ind Pharm. 1994;20:1829.

Hua S. Lipid-based nano-delivery systems for skin delivery of drugs and bioactives. Front Pharmacol. 2015;6:219.

Hussan R. Nanoemulsion as a novel transdermal drug delivery system. Int J Pharm Sci Res. 2011;2:1938-46 https://doi.org/10.1016/j.molliq.2018.09.025.

Imlmal E, Rekax C. Vehicle influence on in vitro release of glucose: $\mathrm{w} / \mathrm{O}, \mathrm{w} / \mathrm{O} / \mathrm{w}$ and o/w systems compared. J Control Release. 1995;33:349-56.

Iwai H, Fukasawa J, Suzuki T. A liquid crystal application in skin care cosmetics. International Journal Cosmetic Sci. 1998;20:87-102.

Jain AK, Thomas NS, Panchagnula R. Transdermal drug delivery of imipramine hydrochloride. I. Effect of terpenes. J Control Release. 2002;79:93-101.

Jean-Louis S. Formulation concepts for emulsion maker. In: Marcel Dekker Nielloud F, Marti-Mestres G, editors. The Pharmaceutical emulsions and suspensions; 2000. p. 20-68.

Kahlweit M, Busse G, Faulhaber B. Preparing nontoxic microemulsions. Langmuir. 1995;11:4185-7. 
Kalia YN, Guy RH. Interaction between penetration enhancers and iontophoresis: effect on human skin impedance in vivo. J Control Release. 1997;44:33-42.

Kanikkannan N, Babu RJ. Structure-activity relationship of chemical penetration enhancers. In: Dragicevic N, Maibach HI, editors. Percutaneous penetration enhancers chemical methods in penetration enhancement: modification of the stratum corneum. Berlin, Heidelberg: Springer Berlin Heidelberg; 2015. p. 39-54. https://doi.org/10.1007/978-3-662-47039-8_4.

Kanikkannan N, Kandimalla K, Lamba SS, Singh M. Structure-activity relationship of chemical penetration enhancers in transdermal drug delivery. Curr Med Chem. 2000;7(6):593-608 https://doi.org/10.2174/0929867003374840.

Karande P, Jain A, Ergun K, Kispersky V, Mitragotri S. Design principles of chemical penetration enhancers for transdermal drug delivery. Proc Natl Acad Sci U S A. 2005;102:4688-93.

Karande $\mathrm{P}$, Jain A, Mitragotri S. Discovery of transdermal penetration enhancers by high-throughput screening. Nat Biotechnol. 2004;22:192-7.

Katz M, Poulsen BJ. Absorption of drugs through the skin. In: Concepts in biochem pharmacol. Berlin Heidelberg: Springer-Verlag; 1971;3(1). p. 103-104. https://doi.org/10.1007/978-3-642-65052-9_7.

Lampe MA, Burlingame AL, Whitney J, Williams ML, Brown BE, Roitman E, Elias PM. Human stratum corneum lipids: characterization and regional variations. J Lipid Res. 1983;24:120-30.

Lashmar UT, Hadgraft J, Thomas N. Topical application of penetration enhancers to the skin of nude mice-a histopatholgical study. J Pharm Pharmacol. 1989;41:188-22.

Lawrence MJ, Rees GD. Microemulsion-based media as novel drug delivery systems. Adv Drug Delivery Rev. 2012;64(Suppl):175-93.

Lupi FR, Gentile L, Gabriele D, Mazzulla S, Baldino N, de Cindio B. Olive oil and hyperthermal water bigels for cosmetic uses. J Colloid Interface Sci. 2015;459:70-8.

Mathur V, Satrawala Y, Rajput M. Physical and chemical penetration enhancers in transdermal drug delivery system. Asian J Pharm. 2010;4:173.

McClements DJ, Decker EA, Weiss J. Emulsion-based delivery systems for lipophilic bioactive components. J Food Sci. 2007;72:R109-24.

Mckenzie AW, Stoughton RB. Method for comparing percutaneous absorption of steroids. Arch Dermatol. 1962;86.

McNaught AD, Wilkinson A. Volume of activation; 1997. p. 1598. https://doi.org/ 10.1351/goldbook.V06644

Michaels AS, Chandrasekaran SK, Shaw JE. Drug permeation through human skin: theory and invitro experimental measurement. AlChE J. 1975;21:985-96.

Mitragotri S. Synergistic effect of enhancers for transdermal drug delivery. Pharm Res. 2000:17:1354-9.

Mitragotri S, Ray D, Farrell J, Tang H, Yu B, Kost J, et al. Synergistic effect of lowfrequency ultrasound and sodium lauryl sulfate on transdermal transport. J Pharm Sci. 2000;89:892-900.

Montenegro L, Lai F, Offerta A, Sarpietro MG, Micicchè L, Maccioni AM, et al. From nanoemulsions to nanostructured lipid carriers: a relevant development in dermal delivery of drugs and cosmetics. J Drug Deliv Sci and Technol. 2016;32:100-12.

Monti D, Saettone MF, Giannaccini B, Galli-Angeli D. Enhancement of transdermal penetration of dapiprazole through hairless mouse skin. J Control Release. 1995:33:71-7

Moore DJ, Rerek ME. Insights into the molecular organization of lipids in the skin barrier from infrared spectroscopy studies of stratum corneum lipid models. Acta Derm Venereol Suppl (Stockh). 2000;208:16-22.

Morimoto K, Tojima H, Haruta T, Suzuki M, Kakemi M. Enhancing effects of unsaturated fatty acids with various structures on the permeation of indomethacin through rat skin. J Pharm Pharmacol. 1996;48:1133-7.

Morrow DIJ, McCarron PA, Woolfson AD, Donnelly RF. Innovative strategies for enhancing topical and transdermal drug delivery. TODDJ. 2007;1:36-59.

Mu L, Sprando RL. Application of nanotechnology in cosmetics. Pharm Res. 2010; 27:1746-9

Narishetty ST, Panchagnula R. Transdermal delivery of zidovudine: effect of terpenes and their mechanism of action. J Control Release. 2004;95:367-79.

Noor MD, Zainab EJ, Mowafaq MG, Hiba Z. Studying the effect of different gelling agent on the preparation and characterization of metronidazole as topical emulgel. Asian J Pharm Clin Res. 2019;12(3):571-7 https://doi.org/10. 22159/ajpcr.2019.v12i3.31504.

Ogiso T, Tanino T. Transdermal delivery of drugs and enhancement of percutaneous absorption. Yakugaku Zasshi. 2000;120:328-38.

Otberg N, Richter H, Schaefer H, Blume-Peytavi U, Sterry W, Lademann J. Variations of hair follicle size and distribution in different body sites. J Invest Dermatol. 2004;122:14-9.
Otto A, du Plessis J, Wiechers JW. Formulation effects of topical emulsions on transdermal and dermal delivery. Int J Cosmet Sci. 2009;31:1-19.

Pathan IB, Setty CM. Chemical penetration enhancers for transdermal drug delivery systems. Trop J Pharm Res. 2009:8:173-9.

Patravale VB, Mandawgade SD. Novel cosmetic delivery systems: an application update. Int J Cosmet Sci. 2008:30:19-33.

Peppas NA, Bures P, Leobandung W, Ichikawa H. Hydrogels in pharmaceutical formulations. Eur J Pharm Biopharm. 2000;50:27-46.

Pfister WR, Hsieh DS. Permeation enhancers compatible with transdermal drug delivery systems. Part I: Selection and formulation considerations. Med Device Technol. 1990;1:48-55.

Pham QD, Björklund S, Engblom J, Topgaard D, Sparr E. Chemical penetration enhancers in stratum corneum - relation between molecular effects and barrier function. J Control Release. 2016;232:175-87.

Pillai O, Panchagnula R. Transdermal delivery of insulin from poloxamer gel: ex vivo and in vivo skin permeation studies in rat using iontophoresis and chemical enhancers. J Controlled Release. 2003:89:127-40.

Prausnitz MR, Langer R. Transdermal drug delivery. Nat Biotechnol. 2008;26:1261-8.

Puri A, Murnane KS, Blough BE, Banga AK. Effects of chemical and physical enhancement techniques on transdermal delivery of 3-fluoroamphetamine hydrochloride. Int J Pharm. 2017:528:452-62.

Reed JT, Ghadially R, Elias PM. Skin type, but neither race nor gender, influence epidermal permeability barrier function. Arch Dermatol. 1995;131:1134-8.

Rehman K, Zulfakar MH. Recent advances in gel technologies for topical and transdermal drug delivery. Drug Dev Ind Pharm. 2014;40:433-40.

Rodrigues Ueoka A, Pedriali MC. Development and stability evaluation of liquid crystal-based formulations containing glycolic plant extracts and nanoactives. Cosmetics. 2018:5:25.

Roskos KV, Maibach HI, Guy RH. The effect of aging on percutaneous absorption in man. J Pharmacokinet Biopharm. 1989;17:617-30.

Sapra B, Jain S, Tiwary AK. Percutaneous permeation enhancement by terpenes: mechanistic view. AAPS J. 2008;10:120-32.

Scheuplein RJ. Mechanism of percutaneous absorption. II. Transient diffusion and the relative importance of various routes of skin penetration. J Invest Dermatol. 1967:48:79-88.

Seto JE, Polat BE, Lopez RFV, Blankschtein D, Langer R. Effects of ultrasound and sodium lauryl sulfate on the transdermal delivery of hydrophilic permeants: comparative in vitro studies with full-thickness and split-thickness pig and human skin. J Control Release. 2010;145:26-32.

Shakeel A, Lupi FR, Gabriele D, Baldino N, De Cindio B. Bigels: a unique class of materials for drug delivery applications. Soft Materials. 2018;16:77-93.

Shen C, Shen B, Liu X, Yuan H. Nanosuspensions based gel as delivery system of nitrofurazone for enhanced dermal bioavailability. J Drug Deliv Sci Tech. 2018:43:1-11.

Smith EW, Surber C, Tassopoulos T, Maibach HI. Topical dermatological vehicles: a holistic approach. In: Topical absorption of dermatological products: CRC Press; 2002. p. 472-9. https://doi.org/10.3109/9780203904015.

Som I, Bhatia K, Yasir M. Status of surfactants as penetration enhancers in transdermal drug delivery. J Pharm Bioallied Sci. 2012;4:2-9.

Sommer E, Neubert RHH, Mentel M, Tuchscherer B, Mrestani Y, Wohlrab J. Dermal peptide delivery using enhancer molecules and colloidal carrier systems. Part III. Tetrapeptide GEKG. Eur J Pham Sci. 2018;124:137-44.

Soni V, Chandel S, Jain P, Asati S: 2016. Role of liposomal drug-delivery system in cosmetics. In: Nanobiomaterials in galenic formulations and cosmetics. WA Press; 2016. p. 93-120. https://doi.org/10.1016/C2015-0-00402-6.

Sonneville-Aubrun O, Simonnet JT, L'Alloret F. Nanoemulsions: a new vehicle for skincare products. Adv Colloid Interface Sci. 2004;108-109:145-9.

Stubenrauch C, Paeplow B, Findenegg GH. Microemulsions supported by octyl monoglucoside and geraniol. 1. The Role of the Alcohol in the Interfacial Layer. Langmuir. 1997;13:3652-8.

Sugibayashi K, Nakayama S, Seki T, Hosoya Kl, Morimoto Y. Mechanism of skin penetration-enhancing effect by laurocapram. J Pharm Sci. 1992:81:58-64.

Swenson ES, Curatolo WJ. (C) Means to enhance penetration: (2) intestinal permeability enhancement for proteins, peptides and other polar drugs: mechanisms and potential toxicity. Adv Drug Delivery Rev. 1992;8(1):39-92.

Tharwat T. Surfactants. In: Encyclopedia of colloid and interface science. Berlin, Heidelberg: Springer; 2013. https://doi.org/10.1007/978-3-642-20665-8.

Thomas BJ, Finnin BC. The transdermal revolution. Drug Discov Today. 2004;9:697-703.

Touitou E, Dayan N, Bergelson L, Godin B, Eliaz M. Ethosomes - novel vesicular carriers for enhanced delivery: characterization and skin penetration properties. J Control Release. 2000;65:403-18. 
Trommer H, Neubert RH. Overcoming the stratum corneum: the modulation of skin penetration. A review. Skin Pharmacol Physiol. 2006;19:106-21.

Uchegbu IF, Florence AT. Non-ionic surfactant vesicles (niosomes): physical and pharmaceutical chemistry. Adv Colloid Interface Sci. 1995;58:1-55.

Verma DD, Fahr A. Synergistic penetration enhancement effect of ethanol and phospholipids on the topical delivery of cyclosporin A. J Control Release. 2004; $97: 55-66$.

Verma P, Pathak K. Therapeutic and cosmeceutical potential of ethosomes: an overview. J Adv Pharm Technol Res. 2010;1(3):274-82. https://doi.org/10. 4103/0110-5558.72415.

Vintiloiu A, Leroux JC. Organogels and their use in drug delivery - a review. J Control Release. 2008;125:179-92.

Walker RB, Smith EW. The role of percutaneous penetration enhancers. Adv. Drug Delivery Rev. 1996;18:295-301.

Wertz PW, Schwartzendruber DC, Madison KC, Downing DT. Composition and morphology of epidermal cyst lipids. J Invest Dermatol. 1989;35:1-17 https:// doi.org/10.1111/1523-1747.ep12471781.

Wichterle O, Lím D. Hydrophilic gels for biological use. Nature. 1960;185:117-8.

Williams AC, Barry BW. Penetration enhancers. Advanced Drug Delivery Reviews. 2004;56(5):603-18. 10.1186/s41702-020-0058-7.

Williams AC, Barry BW. Penetration enhancers. Adv. Drug Delivery Rev. 2012; 64(Suppl):128-37.

Wong O, Tsuzuki N, Nghiem B, Kuehnhoff J, Itoh T, Masaki K, et al. Unsaturated cyclic ureas as new non-toxic biodegradable transdermal penetration enhancers: II. Evaluation study. Int J Pharm. 1989;52:191-202.

Yang Y, Kalluri H, Banga AK. Effects of chemical and physical enhancement techniques on transdermal delivery of cyanocobalamin (vitamin B12) in vitro. Pharmaceutics. 2011;3:474-84.

Yarosh D, Klein J. The role of liposomal delivery in cutaneous DNA repair. Adv Drug Delivery Rev. 1996;18:325-33.

Yarosh DB. Liposome dermatics. J Invest Dermatol. 1992;98:818.

\section{Publisher's Note}

Springer Nature remains neutral with regard to jurisdictional claims in published maps and institutional affiliations.

Ready to submit your research? Choose BMC and benefit from:

- fast, convenient online submission

- thorough peer review by experienced researchers in your field

- rapid publication on acceptance

- support for research data, including large and complex data types

- gold Open Access which fosters wider collaboration and increased citations

- maximum visibility for your research: over $100 \mathrm{M}$ website views per year

At $\mathrm{BMC}$, research is always in progress.

Learn more biomedcentral.com/submissions 